\title{
The Slow Dawn of Climate-Change Awareness, and Its Challenge for a Sustainable Planet
}

\author{
Lawrence C. Hamilton
}

\begin{abstract}
The Carsey Perspectives series presents new ways of looking at issues affecting our society and the world. Any opinions, findings, and conclusions or recommendations expressed in this material are those of the author and do not necessarily reflect the views of the sponsors or publisher.
\end{abstract}

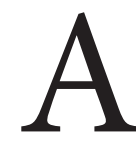

mong scientists there is overwhelming agreement that human activities are changing Earth's climate. ${ }^{1}$ Yet U.S. public awareness of that scientific consensus remains deeply divided, mainly along political lines. While opposition from conservative leaders and media delay public acceptance, surveys suggest that, overall, recognition of human-caused climate change has been gradually rising. ${ }^{2}$ Figure 1 charts the percentage agreeing that "climate change is happening now, caused mainly by human activities," across 5 U.S. nationwide and $41 \mathrm{New}$ Hampshire statewide surveys, conducted from April 2010 to July 2020 with independent random samples totaling almost 30,000 respondents. Background information about the individual surveys and climate-change questions can be found in earlier papers. ${ }^{3}$

Figure 1 also marks some events that were, at the time, widely speculated to affect public views on climate change-such as disastrous hurricanes in 2012, 2017, 2018, and 2019; or more positively, a major report by the Intergovernmental Panel on Climate Change in 2013, and Pope Francis' 2015 encyclical on climate change in which he warned of "serious consequences for all of us" if humanity failed to act. Seen in this graph's decade-long perspective, however, none of those events were followed by more than a transient blip in climate-change opinions. But we do see a gradual, statistically significant rise from around half of respondents agreeing in 2010 to about two-thirds by 2020 .

Although Figure 1 shows no immediate effects from sudden events, their influence might have gradually accumulated by adding to public awareness. Research by thousands of scientists across many fields, a small

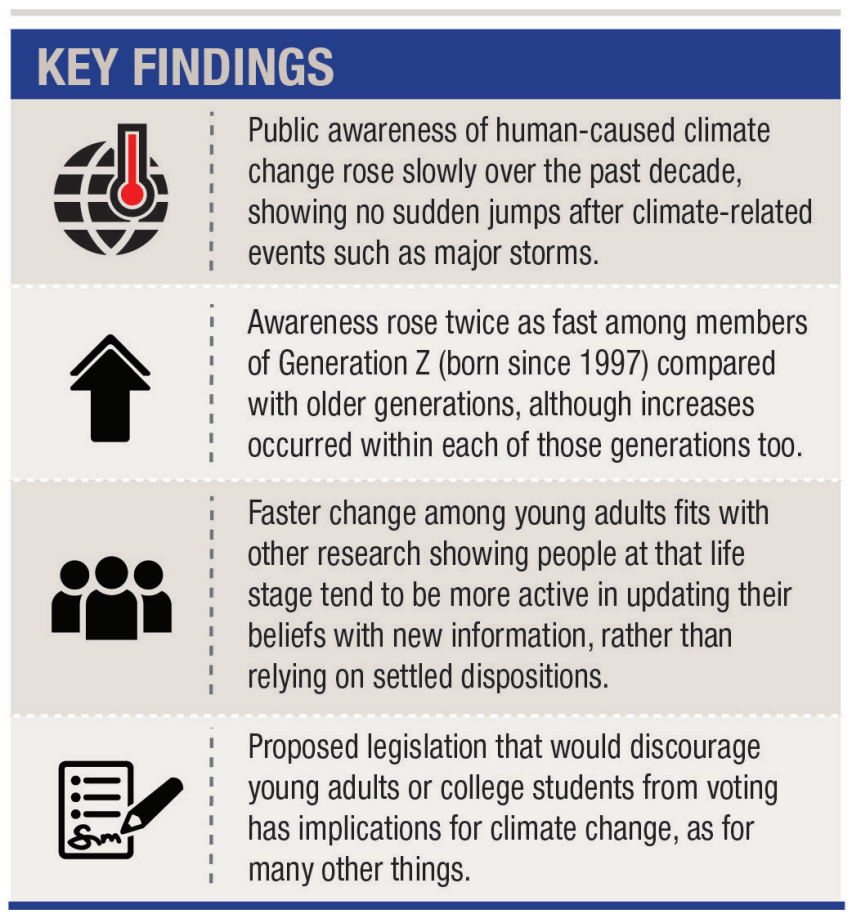

fraction of it filtering into news accounts and even weather reports, contributed to growing salience. Globally over this decade, scientists observed steadily rising $\mathrm{CO}_{2}$ concentrations (reaching the highest levels in 3.6 million years) ${ }^{4}$ and deep-ocean heat content, while average surface temperatures repeatedly surpassed those of previous decades, and both Arctic and Antarctic sea ice melted to new lows. Other influences might include personal experience with the rising frequency of extreme-weather events such as wildfires, droughts, flooding, and storms-or changes to familiar seasons such as shorter, warmer winters in snow country. In New Hampshire, for example, the years spanned by the 41 state surveys in Figure 1 included the two warmest winters, as well as the three earliest ice-out dates for Lakes Sunapee and Winnipesaukee, according to historical records dating back to the 1800 s. ${ }^{5}$ Different kinds of influences could be mutually reinforcing. And yet, as Figure 1 shows, their combined impact on public opinion has been mild. 
The relatively mild rise in public acceptance of climate change, despite physical evidence and overwhelming agreement among scientists - to say nothing of their increasingly urgent calls for action-reflects the degree to which climate beliefs have, through top-down campaigns, ${ }^{6}$ become firmly anchored to sociopolitical identity. ${ }^{7}$ Recent longitudinal research by political scientists Kevin Kiley and Stephen Vaisey, analyzing responses from the same individuals on repeated surveys covering a wide range of topics (but not climate change), found that for most questions people's responses showed little year-to-year change, instead reflecting settled dispositions that they developed prior to adulthood. ${ }^{8}$ Only a few questions showed much evidence of people actively updating their views as they acquire new information. Active updating occurs more often with high-profile issues, however, a category that could include climate change. Seen in that light, the slow rise tracked in Figure 1 probably represents both processes: the inertia of settled, identity-linked dispositions, partly offset by some people updating their views with new information from current events, scientists, and personal experience.

Although Kiley and Vaisey found that active updating of opinions was limited overall, it occurred somewhat more often among one subgroup: young adults. That insight motivates the new analysis in Figure 2, which separates the 24,065 New Hampshire responses of Figure 1 into trend lines for each of six generations, defined by year of birth. Generation Z, born

\section{FIGURE 1: PERCENT OF RESPONDENTS WHO AGREE THAT "CLIMATE CHANGE IS HAPPENING NOW, CAUSED MAINLY BY HUMAN ACTIVITIES" ON 46 NEW HAMP- SHIRE AND U.S. NATIONWIDE SURVEYS FROM APRIL 2010 THROUGH JULY 2020.}

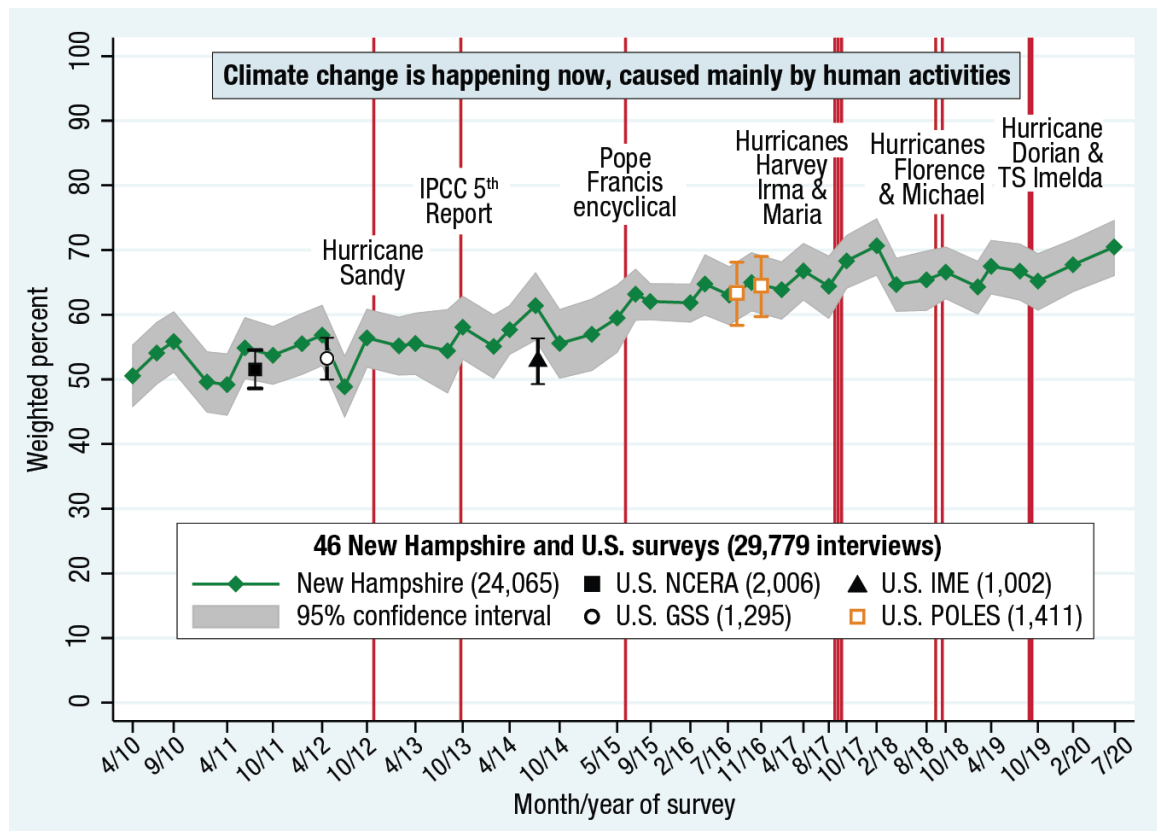

Note: Gray bands (New Hampshire surveys' estimates) and error bars (other surveys' estimates) indicate $95 \%$ confidence intervals. Red bars indicate significant climate-related events. Source: National Community and Environment in Rural America (NCERA), General Social Survey (GSS), IMedia Ethics (IME), and Polar, Environment, and Science (POLES).

since 1997 (and first entering these surveys in 2015) stands out with a steeper trend. Acceptance of human-caused climate change rose twice as fast among Gen $\mathrm{Z}$ respondents as it did among older groups, consistent with Kiley and Vaisey's observation that active updating occurs more often among young adults. Conversely, the slow trends for older generations suggest less active updating. Among these older groups Millennials (born 1981 to 1996) have been most likely to accept human-caused climate change, followed by early Boomers (1946-1955) who came of age during the Vietnam War. Gen $\mathrm{X}$, late Boomers, and the oldest generations (GI and Silent) are less inclined to accept human-caused climate change, although each group exhibits some change.
An unfortunate implication of the finding that settled dispositions often dominate public opinion is that broad change then depends on cohort replacement, or waiting for older generations to fade away and be replaced by newer ones holding different views. Climate opinions do not fit this description in that awareness has been rising both within and between generations. However, the pace, even combined with generational replacement, is dangerously slow compared with the pace of climate change itself.

Practical steps to mitigate the risks of climate change, through climate-aware policies, could be hastened by increased voter participation among those who will disproportionately feel its effects-including young adults, 


\section{FIGURE 2: TRENDS WITHIN SIX GENERATIONS: PERCENTAGE AGREEING THAT "CLIMATE CHANGE IS HAPPENING NOW, CAUSED MAINLY BY HUMAN ACTIVITIES."}

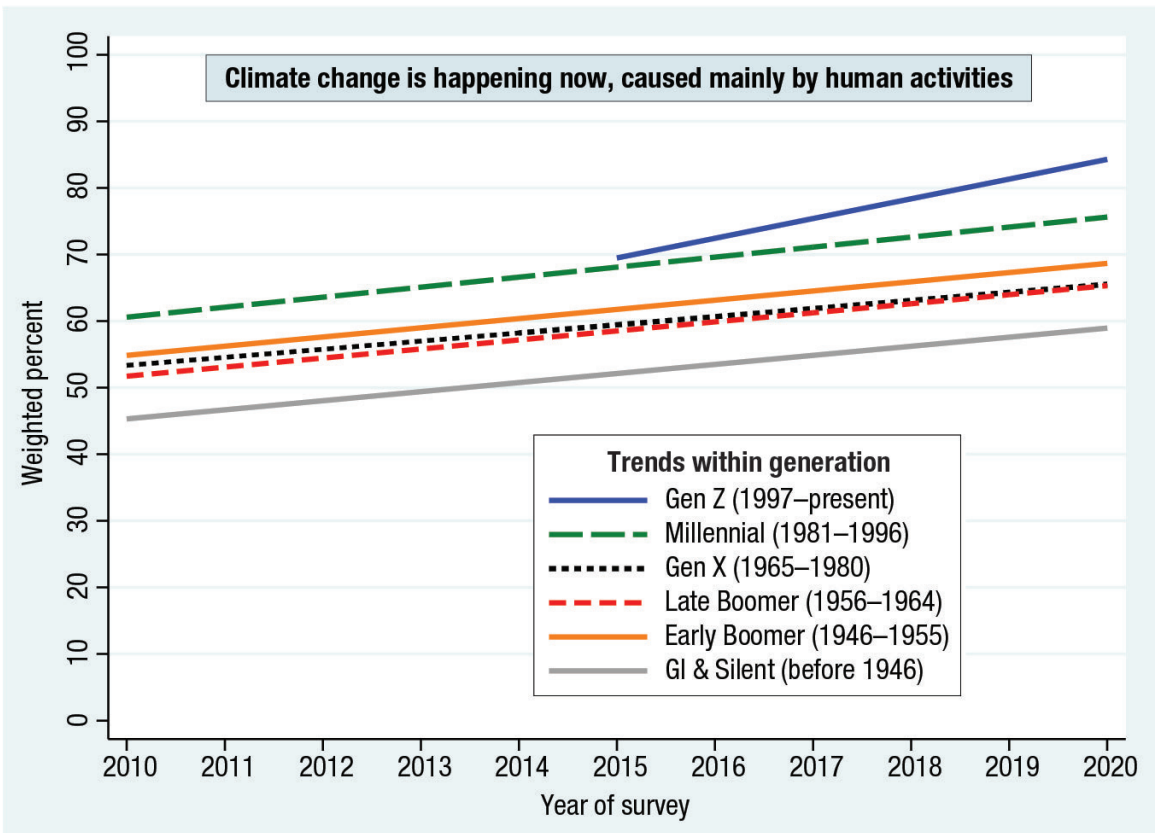

Source: Forty-one New Hampshire surveys (Granite State Poll) from April 2010 to July 2020.

whose longer time horizons expose them to more personal risks. Young-adult voter participation rates in the United States have historically lagged older groups, but in principle such rates could rise quickly. In the 2020 presidential election an estimated 53 to 56 percent of the eligible population under 30 voted, up from 45 to 48 percent in 2016 - and their impact was important. ${ }^{9}$ Because of generational differences in views, however, legislation discouraging participation by young voters could have long-lasting consequences. For example, in 2021, New Hampshire's state legislature is considering several bills that would make it more difficult for college students to vote. ${ }^{10}$ The outcome of such efforts could shape the future in many ways, from local issues up to Earth's climate.

\section{Endnotes}

1. J. Cook, N. Oreskes, P.T. Doran, W.R.L. Anderegg, B. Verheggen, E.W. Maibach, J.S. Carlton, S. Lewandowsky, A.G. Skuce, and S.A. Green. "Consensus on consensus: A synthesis of consensus estimates on human-caused global warming." Environmental Research Letters; 2016 11(4). https://doi. org/10.1088/1748-9326/11/4/048002

2. L.C. Hamilton, "Public awareness of the scientific consensus on climate." Sage Open; 2016. https://doi. org/10.1177/2158244016676296

3. L.C. Hamilton, J. Hartter, M. LemckeStampone, D.W. Moore, and T.G. Safford. "Tracking public beliefs about anthropogenic climate change." PLoS One; 2015. https://doi.org/10.1371/journal. pone.0138208; L.C. Hamilton, J. Hartter, and E. Bell. "Generation gaps in U.S. public opinion on renewable energy and climate change." PLoS One; 2019. https:// doi.org/10.1371/journal.pone.0217608

4. National Oceanic and Atmospheric Administration, "Despite pandemic shutdowns, carbon dioxide and methane surged in 2020." April 7, 2021. https:// research.noaa.gov/article/ArtMID/587/ ArticleID/2742/Despite-pandemicshutdowns-carbon-dioxide-andmethane-surged-in-2020

5. E.A. Burakowski and L.C. Hamilton. "Are New Hampshire's winters warming? Yes, but fewer than half of state residents recognize the trend." Durham, NH: Carsey School of Public Policy 2020. http://scholars.unh.edu/carsey/389

6. R.E. Dunlap and A.M. McCright. "Challenging climate change: The denial countermovement." 300-332 in R.E. Dunlap \& R.J. Brulle (eds.) Climate Change and Society: Sociological Perspectives, 2015. New York: Oxford University Press.

7. L.C. Hamilton, J. Hartter, and C. Grimm. "Sociopolitical silos: Environmental views and the multiplicative effects of same-party friends," 2020. https://scholars.unh.edu/ faculty_pubs/923/

8. K. Kiley and S. Vaisey. "Measuring stability and change in personal culture using panel data." American Sociological Review 2020, 85(3): 477-506. https://doi. org/10.1177/0003122420921538; S. Vaisey \& K. Kiley. "A model-based method for detecting persistent cultural change using panel data." Sociological Science 2021, 8: 83-95. https://doi.org/10.15195/v8.a5

9. CIRCLE (Center for Information and Research on Civic Learning and Engagement). "Election week 2020: Young people increase turnout, lead Biden to victory." Tufts University 2020. https://circle.tufts.edu/latest-research/ election-week-2020\#youth-voterturnout-increased-in-2020

10. H. Ramer. "GOP bills to tighten voter eligibility again target students." Associated Press, March 8, 2021. https://apnews.com/article/newhampshire-voting-voting-rightselections-coronavirus-pandemicaa0bbe26136ce85ecfdf0e19c10b55ed

\section{About the Author}

Lawrence C. Hamilton is professor of sociology and senior fellow at the Carsey School of Public Policy at the University of New Hampshire. 


\section{See related publications at carsey.unh.edu}

- E.A. Burakowski and L.C. Hamilton. 2020. "Are New Hampshire's winters warming? Yes, but fewer than half of state residents recognize the trend." http://scholars.unh.edu/carsey/389

- L.C. Hamilton. 2019. "Climate-change views of New Hampshire primary voters." https:// scholars.unh.edu/carsey/373/

- L.C. Hamilton. 2018. "Millennials and climate change." https://scholars.unh.edu/carsey/337/

- L.C. Hamilton. 2018. "Public awareness of scientific consensus on climate change is rising." https://scholars.unh.edu/carsey/336/

- L.C. Hamilton. 2017. "Public acceptance of human-caused climate change is gradually rising." http://scholars.unh.edu/carsey/322/

- L.C. Hamilton. 2017. "Public support for environmental protection.” Durham, NH: Carsey School of Public Policy. http://scholars.unh.edu/carsey/295/

- L.C. Hamilton, J. Brunacini, and S. Pfirman. 2017. "Eyes off the Earth: Public opinion regarding climate science and NASA." Durham, NH: Carsey School of Public Policy. http://scholars.unh. edu/carsey/308/

- L.C. Hamilton. 2017. "On renewable energy and climate, Trump voters stand apart." Durham, NH: Carsey School of Public Policy. http://scholars.unh.edu/carsey/293/

- L.C. Hamilton. 2016. "Where is the North Pole? An election-year survey on global change." Durham, NH: Carsey School of Public Policy. http://scholars.unh.edu/carsey/285/

- L.C. Hamilton and M. Lemcke-Stampone. 2016. "Was December warm? Family, politics, and recollections of weather." Durham, NH: Carsey School of Public Policy. http://scholars.unh. edu/carsey/276/

The Carsey School of Public Policy at the University of New Hampshire is nationally recognized for its research, policy education, and engagement. The school takes on the pressing issues of the twenty-first century, striving for innovative, responsive, and equitable solutions.

Huddleston Hall • 73 Main Street • Durham, NH 03824

(603) 862-2821

TTY Users: DIAL 7-1-1 OR 1-800-735-2964 (RELAY N.H.)

carsey.unh.edu 